\title{
HUBUNGAN KARAKTERISTIK IBU DENGAN KEJADIAN ABORTUS DI RSU MUHAMMADIYAH MEDAN TAHUN 2020
}

\author{
Siti Arofah ${ }^{1}$, Rapida Saragih ${ }^{2}$ \\ ${ }^{I}$ Fakultas Keperawatan dan Kebidanan, Universitas Prima Indonesia Medan, \\ ${ }^{2}$ Fakultas Kesehatan Masyarakat Universitas Haji Medan \\ Email:aarofah4@gmail.com; pida81saragih@gmail.com
}

\begin{abstract}
According to the World Health Organization (WHO), 15-50\% of maternal deaths are caused by abortion. Data shows the possibility of a fairly high percentage, approximately $15-40 \%$ the number of known occurrences on mothers who already stated positively pregnant, and 60-75\% of abortion occurs before the pregnancy reaches 12 weeks. This research investigates the relationship between the mother's characteristics with the abortion case in the RSU Muhammadiyah. The investigation was conducted in a crosssectional analysis. The population is 42 mothers who experienced abortion in the RSU Muhammadiyah based on medical record year 2020. Statistical analysis using chi-square with the p-value of age, parity, and education parameters are 0,002, 0.017, and 0.004 respectively. This data showed that there was a relationship between age, parity, and education with abortion cases in RSU Muhammadiyah Medan. This report might be useful for the government and stakeholders in controlling the abortion case in Medan.
\end{abstract}

Keywords: Age, parity, abortion case

PENDAHULUAN

Kehamilan merupakan suatu dambaan seseorang wanita yang dapat membuat mereka bahagia dalam keluarga. Kehamilan ini terjadi secara fisiologis pada setiap wanita. Perubahan fisik dan psikologis pada masa kehamilan pada setiap wanita ada yang beranggapan hal yang membuat mereka tidak percaya diri dan ada juga yang beranggapan dengan hal yang sangat bahagia untuk memulai kehidupan yang baru. Abortus atau keguguran adalah terhentinya kehamilan sebelum janin dapat bertahan hidup, yaitu sebelum kehamilan berusia 22 minggu atau berat janin belum mencapai 500 gram. Pada masa kehamilan sangat perlu pemeriksaan kehamilan untuk mengetahui adanya tanda-tanda bahaya dalam kehamilan ibu (Rukiyah, 2013).

Abortus adalah berakhirnya suatu kehamilan (oleh akibat-akibat tertentu) atau sebelum kehamilan tersebut berusia 22 minggu atau buah kehamilan belum mampu untuk hidup diluar kandungan. Abortus biasanya ditandai dengan terjadinya perdarahan pada wanita yang sedang hamil, dengan adanya peralatan USG. Pada penelitian yang mengamati hubungan antara usia ibu pada saat kehamilan dan terjadinya abortus mendapatkan usia 12-19 tahun risiko abortus 13\%, 20-24 tahun 11\%, usia 25-29 tahun risiko abortus 13\%, 20-24 tahun $11 \%$, usia $25-19$ tahun $12 \%$, 30- 
40 tahun $15 \%$, 35-39 tahun 25\%, 40-44 tahun $51 \%$ dan $\geq 45$ tahun $93 \%$. Peningkatan usia pasangan pria merupakan faktor risiko abortus lainnya (Rukiyah, 2013).

Risiko tertinggi terjadinya abortus bila usia ibu $\geq 35$ tahun dan pasangan pria $\geq 40$ tahun. Paritas ibu adalah keadaan wanita berkaitan dengan jumlah anak yang dilahirkan. Paritas anak kedua dan anak ketiga merupakan paritas paling aman ditinjau dari sudut kematian maternal. Pada paritas tinggi lebih dari 3 mempunyai angka kematian maternal lebih tinggi (Rukiyah, 2013).

Pada paritas rendah, ibu-ibu hamil belum begitu mengerti tentang kehamilan pada pentingnya pemeriksaan kehamilan. Ibu-ibu yang mempunyai anak < 3 (paritas rendah) dapat dikategorikan pemeriksaan kehamilan dengan kategori baik (Walyani, 2015). Tingkat pendidikan sangat mempengaruhi seseorang untuk bertindak dan mencari penyebab serta solusi dalam hidupnya. Ibu yang berpendidikan tinggi akan memeriksakan kehamilannya secara teratur demi menjaga keadaan kesehatan dirinya dan anak dalam kandungannya.

\section{Menurut World Health Organization} (WHO) $\quad 15-50 \%$ kematian ibu disebabkan oleh abortus. Sekitar 15$40 \%$ angka kejadian, diketahui pada ibu yang sudah dinyatakan positif hamil, dan $60-75 \%$ angka abortus terjadi sebelum usia kehamilan mencapai 12 minggu. Terjadi 20 juta kasus abortus di dunia tiap tahun dan 70.000 wanita meninggal karena abortus tiap tahunnya. Angka kematian ibu dan bayi yang tertinggi di Asia Tenggara adalah 4,2 juta pertahun termasuk Indonesia, sedangkan frekuensi abortus spontan di Indonesia adalah 10-15\% dari 6 juta kehamilan setiap tahunya atau 600.000900.000, sedangkan abortus buatan sekitar 0,75-1,5 juta tiap tahunya, 2500 orang diantaranya berakhir dengan kematian (Pariani, 2020).

Berdasarkan Survey Demografi dan Kesehatan Indonesia (SDKI) Tahun 2013 menunjukkan bahwa terdapat AKI dari 128 menjadi 102 per 100.000 kelahiran hidup. Penyebab AKI di Indonesia adalah perdarahan $25 \%$ eklamsia $24 \%$ infeksi $11 \%$, komplikasi masa puerperium $8 \%$, emboli obstetri $3 \%$, partus lama atau partus macet $3 \%$, abortus 5\%. (P, 2014). Pada tahun 2012 AKI di indonesia masih diatas 200 setiap 100 ribu kelahiran, sedangkan capaian MDG's pada tahun 2015 angka kematian ibu maksimal 100 ribu kelahiran salah satu penyebab dari kematian ibu adalah abortus (Aini, 2016).

Berdasarkan Profil Kesehatan Provinsi Sumatera Utara 2012 diperoleh bahwa terdapat 469 kasus abortus dari 
6,323 total persalinan. Sebanyak 10,11\% abortus sebenarnya mendekati angka $50 \%$ sebagai penyumbang AKI, namun lebih sering dilaporkan dalam bentuk abortus. Semua ibu hamil yang memeriksakan kehamilannya dengan usia trimester I dan trimester II dengan usia hamil 20-35 tahun mayoritas pendidikan kesehatannya tentang abortus masih dalam kategori kurang (Rasidah, 2015). Penelitian Gustina menyatakan bahwa $90 \%$ dari ibu hamil yang mengalami abortus merupakan ibu dengan pendidikan rendah. Hal ini dapat terjadi karena pada ibu dengan pendidikan rendah cenderung kurang memperhatikan kesehatan dirinya terutama kehamilannya (Aini, 2016).

Berdasarkan hasil survei awal yang dilakukan oleh peneliti di RSU. Muhammadiyah Medan tahun 2020 diketahui bahwa ibu yang mengalami abortus ada 42 orang kasus yang abortus. dimana dari hasil artikel penelitian orang lain kejadian abortus penyebab yang paling dominan adalah umur, pendidikan dan paritas, sehingga kebaharuan dalam penelitian ini masih dengan instrumen yang sama dengan penelitian yang lain, sehingga peneliti melakukan pengembangan tentang instrumen yang sudah diukur dan dilakukan pengembangan kembali di Rumah sakit yang berbeda dengan instrumen yang sama.

\section{METODE}

Jenis penelitian ini menggunakan survei analitik dengan pendekatan bedah lintang (cross sectional study). Tempat penelitian dilakukan di RSU Muhammaddiyah Medan.

Populasi dalam penelitian ini adalah semua ibu hamil yang mengalami abortus sebanyak 42 orang. Sampel pada penelitian ini adalah ibu hamil yang mengalami abortus sebanyak 42 orang Teknik pengambilan sampel dengan menggunakan cara total populasi yaitu dimana seluruh ibu hamil yang mengalami abortus.

Pengumpulan data yang dilakukan dalam penelitian ini diperoleh dari hasil dokumentasi oleh pihak lain, misalnya rekam medik, rekapitulasi, nilai, dan kunjungan pasien dan lain-lain.

Analisis data menggunakan analisa univariat dan bivariat. Analisa univariat digunakan untuk mendeskripsikan data yang dilakukan pada tiap variabel dari hasil penelitian. Data yang disajikan dalam tabel distribusi frekuensi. Analisa bivariat untuk membuktikan adanya hubungan antara variabel bebas dengan variabel terikat digunakan uji ChiSquare, pada batas kemaknaan perhitungan statistik p-volue $(0,05)$ Kemudian untuk menjelaskan adanya asosiasi (hubungan) antara variabel terikat dengan variabel bebas digunakan analisis tabulasi silang (Muhammad, 2020). 


\section{HASIL DAN PEMBAHASAN}

\section{Hasil Penelitian}

Tabel 1. Distribusi Frekuensi Ibu yang Mengalami Abortus

\begin{tabular}{lcc}
\hline \multicolumn{1}{c}{ Kategori } & \multicolumn{2}{c}{ Jumlah } \\
\cline { 2 - 3 } & $\boldsymbol{f}$ & $\boldsymbol{\%}$ \\
\hline Abortus & 21 & 50,0 \\
\hline Abortus Inkomplit & 6 & 14,3 \\
Abortus Imminens & 15 & 35,7 \\
Missed Abortus & & \\
\hline Umur & 18 & 42,9 \\
\hline$<20$ tahun & 13 & 31,0 \\
20-35 tahun & 11 & 26,2 \\
$>$ 35 tahun & & \\
\hline Paritas & 19 & 42,2 \\
\hline Primigravida & 12 & 28,6 \\
Multigravida & 11 & 26,2 \\
Grandemultigravida & & 7,1 \\
\hline Pendidikan & 3 & 31,0 \\
\hline TK/SD & 13 & 45,2 \\
SMP & 9 & 16,7 \\
SMA & 7 & \\
PT & & \\
\hline
\end{tabular}

Berdasarkan Tabel 1 diatas dapat diketahui bahwa distribusi frekuensi ibu yang mengalami abortus, dari 42 orang (100\%), yang mengalami abortus inkomplit sebanyak 21 orang $(50,0 \%)$, abortus imminens sebanyak 6 orang (14,3\%), dan missed abortus sebanyak 15 orang $(35,7 \%)$.

Berdasarkan Tabel 1 diatas dapat diketahui bahwa distribusi frekuensi ibu hamil berdasarkan umur, dari 42 orang $(100 \%)$ ialah <20 tahun sebanyak 18 orang $(42,9 \%)$, 20-35 tahun sebanyak 13 orang $(31,0 \%)$, dan $>35$ tahun sebanyak 11 orang $(26,2 \%)$.

Berdasarkan Tabel 1 diatas dapat diketahui bahwa distribusi frekuensi ibu hamil berdasarkan paritas, dari 42 orang (100\%) pada ibu yang mempuyai paritas primigravida sebanyak 19 orang $(42,2 \%)$ multigravida sebanyak 12 orang $(28,6 \%)$ dan grandemultigravida sebanyak 11 orang $(26,2 \%)$.

Berdasakan Tabel 1 diatas dapat diketahui distribusi frekuensi ibu hamil berdasarkan pendidikan, dari 42 orang (100\%), ibu yang berpendidikan TK/SD sebanyak 3 orang $(7,1 \%)$, SMP sebanyak 13 orang $(31,0 \%)$ SMA sebanyak 19 orang $(4,2 \%)$ dan PT sebanyak 7 orang $(16,7 \%)$. 
Tabel 2. Hubungan Karakteristik Ibu dengan Abortus

\begin{tabular}{|c|c|c|c|c|c|c|c|c|c|c|}
\hline \multirow{4}{*}{ No } & \multirow{3}{*}{ Karakteristik } & \multicolumn{6}{|c|}{ Abortus } & \multirow{2}{*}{\multicolumn{2}{|c|}{ Jumlah }} & \multirow{3}{*}{ P-value } \\
\hline & & \multicolumn{2}{|c|}{$\begin{array}{c}\text { Abortus } \\
\text { Inkomplit }\end{array}$} & \multicolumn{2}{|c|}{$\begin{array}{l}\text { Abortus } \\
\text { Iminnens }\end{array}$} & \multicolumn{2}{|c|}{$\begin{array}{c}\text { Missed } \\
\text { Abortus }\end{array}$} & & & \\
\hline & & $f$ & $\%$ & $f$ & $\%$ & $f$ & $\%$ & $f$ & $\%$ & \\
\hline & \multicolumn{10}{|l|}{ Umur } \\
\hline 1 & $<20$ tahun & 11 & 26,2 & 5 & 11,9 & 2 & 4,8 & 18 & 42,9 & \multirow{3}{*}{0,002} \\
\hline 2 & 20-35 tahun & 8 & 19,0 & 1 & 2,4 & 4 & 9,5 & 13 & 31,0 & \\
\hline 3 & $>35$ tahun & 2 & 4,8 & 0 & 0 & 9 & 21,4 & 11 & 26,2 & \\
\hline \multicolumn{11}{|c|}{ Paritas } \\
\hline 1 & Primigravida & 12 & 28,6 & 5 & 11,9 & 2 & 4,8 & 19 & 23,8 & \multirow{3}{*}{0,017} \\
\hline 2 & Multigravida & 6 & 14,3 & 0 & 0 & 6 & 14,3 & 12 & 42,2 & \\
\hline 3 & Grandemultigravida & 3 & 7,1 & 1 & 2,4 & 7 & 16,7 & 11 & 31,0 & \\
\hline \multicolumn{11}{|c|}{ Pendidikan } \\
\hline 1 & TK/SD & 3 & 7,1 & 0 & 0 & 0 & 0 & 3 & 7,1 & \multirow{4}{*}{0,004} \\
\hline 2 & SMP & 6 & 14,3 & 5 & 11,9 & 2 & 4,8 & 13 & 31,0 & \\
\hline 3 & SMA & 11 & 26,2 & 1 & 2,4 & 7 & 16,7 & 19 & 45,2 & \\
\hline 4 & PT & 1 & 2,4 & 0 & 0 & 6 & 14,3 & 7 & 16,7 & \\
\hline
\end{tabular}

Berdasarkan Tabel 2 di atas menunjukan bahwa tabulasi silang antara umur ibu dengan abortus dari 42 orang (100\%), dari 42 orang terdapat 18 orang $(42,9 \%)$ yang mengalami abortus pada umur <20 tahun diketahui bahwa terjadi abortus inkomplit sebanyak 11 orang (26,2\%), abortus imminens sebanyak 5 orang (11,9\%), dan missed abortus sebanyak 2 orang $(4,8 \%)$, dari 13 orang $(31,0 \%)$ yang mengalami abortus pada umur 20-35 tahun diketahui bahwa terjadi abortus inkomplit sebanyak 8 orang $(19,0 \%)$, abortus imminens sebanyak 1 orang (2,4\%), dan missed abortus sebanyak 4 orang $(9,5 \%)$, dari 11 orang $(26,2 \%)$ ibu yang mengalami abortus pada umur $>35$ tahun diketahui bahwa terjadi abortus inkomplit sebanyak 2 orang $(4,8 \%)$, abortus imminens sebanyak 0 orang $(0 \%)$ dan missed abortus sebanyak 9 orang $(21,4 \%)$. Hasil chi-square diperoleh bahwa sig-p = $0,002<\alpha(0,05)$ berarti Ha diterima, sehingga ada hubungan umur ibu dengan abortus.

Berdasarkan Tabel 2 di atas menunjukan bahwa tabulasi silang antara paritas ibu hamil dengan abortus, dari 42 orang (100\%), dari 42 orang terdapat 19 orang $(23,8 \%)$ yang mengalami abortus pada primigravida diketahui bahwa terjadi abortus inkomplit sebanyak 12 orang $(28,6 \%)$ abortus imminens sebanyak 5 orang $(11,9 \%)$ dan missed abortus sebanyak 2 orang $(4,8 \%)$, dari 12 orang $(42,2 \%)$ yang mengalami abortus pada multigravida diketahui bahwa terjadi 
abortus inkomplit sebanyak 6 orang $(14,3 \%)$, abortus imminens tidak ada, dan missed abortus sebanyak 6 orang $(14,3 \%)$, dari 11 orang $(31,0 \%)$ yang mengalami abortus pada Grande multigravida dapat diketahui bahwa terjadi abortus inkomplit sebanyak 3 orang $(7,1 \%)$, abortus imminens sebanyak 1 orang $(2,4 \%)$, dan missed abortus sebanyak 7 orang $(16,7 \%)$. Hasil chi-square diperoleh bahwa sig$p=0,017$ dimana lebih kecil dari nilai $(0,05)$ dengan demikian dapat ditarik kesimpulan bahwa ada hubungan paritas ibu dengan abortus.

Berdasarkan Tabel 2 di atas menunjukan bahwa tabulasi silang antara pendidikan ibu dengan abortus yaitu dari 42 orang (100\%) terdapat 3 orang $(7,1 \%)$ ibu yang mengalami abortus pada di tingkat pendidikan TK/SD bahwa terjadi abortus inkomplit sebanyak 3 orang $(7,1 \%)$, abortus imminens tidak ada, dan missed abortus tidak ada, dari 13 orang $(31,0 \%)$ ibu yang mengalami abortus pada tingkat pendidikan SMP bahwa terjadi abortus inkomplit sebanyak 6 orang (14,3\%), abortus imminens sebanyak 5 orang $(11,9 \%)$, dan missed abortus sebanyak 2 orang $(4,8 \%)$, dari 19 orang $(45,2 \%)$ yang mengalami abortus pada tingkat SMA diketahui bahwa terjadi abortus inkomplit sebanyak $11 \quad$ orang $(26,2 \%)$, abortus imminens sebanyak
1 orang (2,4\%) dan missed abortus sebanyak 7 orang $(16,7 \%)$, dari 7 orang $(16,7 \%)$ yang mengalami abortus pada tingkat pendidikan PT bahwa terjadi abortus inkomplit sebanyak 1 orang $(2,4 \%)$, abortus imminens tidak ada dan missed abortus sebanyak 6 orang $(14,3 \%)$. Hasil uji chi-square diperoleh bahwa sig- $p=(0,004)$ dimana lebih kecil dari nilai $(0,05)$ dengan demikian dapat ditarik kesimpulan bahwa ada hubungan pendidikan dengan abortus.

\section{Pembahasan}

Berdasarkan hasil penelitian yang dilakukan dari 42 orang terdapat 18 orang $(42,9 \%)$ yang mengalami abortus pada umur <20 tahun diketahui bahwa terjadi abortus inkomplit sebanyak 11 orang (26,2\%), abortus imminens sebanyak 5 orang (11,9\%), dan missed abortus sebanyak 2 orang (4,8\%), dari 13 orang $(31,0 \%)$ yang mengalami abortus pada umur 20-35 tahun diketahui bahwa terjadi abortus inkomplit sebanyak 8 orang (19,0\%), abortus imminens sebanyak 1 orang $(2,4 \%)$, dan missed abortus sebanyak 4 orang $(9,5 \%)$, dari 11 orang $(26,2 \%)$ yang mengalami abortus pada umur $>35$ tahun diketahui bahwa terjadi abortus inkomplit sebanyak 2 orang $(4,8 \%)$, abortus imminens tidak ada dan missed abortus sebanyak 9 orang $(21,4 \%)$. Berdasarkan hasil uji chi-square yang dilakukan oleh peneliti memperlihatkan bahwa nilai $p$ 
sebesar 0,004 berarti ada hubungan antara umur dengan abortus.

Umur ibu dan jumlah abortus sebelumnya merupakan 2 faktor risiko independen yang meningkatkan risiko kejadian abortus pada kehamilan selanjutnya. Peningkatan usia ibu berhubungan dengan penurunan jumlah dan kualitas sisa oosit (Pribadi, 2015).

Umur sangat menentukan kesehatan ibu, ibu dikatakan beresiko tinggi apabila ibu hamil berusia dibawah 20 tahun dan diatas 35 tahun. Berdasarkan penelitian Juwaher cakupan yang memiliki umur 20-35 tahun (tidak resti) sebagian besar melakukan pemeriksaan kehamilan sesuai dengan standar $(\leq 4$ kali) dibandingkan dengan yang berumur $<20$ atau $>35$ tahun (resti) (Juwaher, 2010).

Pada umumnya, ibu hamil yang usianya yang terlalu muda atau terlalu tua sering mendapat penyulit kehamilan. Saat hamil muda terjadi hiperemesis gravidarum atau abortus, dan hamil tua sering terjadi anemia, preeklamsia, dan eklamsia. Usia ibu yang sehat untuk hamil berkisar antara 20- 35 tahun. Ibu yang usianya terlalu muda pada saat hamil, ditinjau dari segi fisik kematangan organ reproduksinya, belum siap untuk menerima kehamilan, demikian pula keseimbangan hormon kewanitaannya belum optimal (Mandriwati, 2020).
Menurut asumsi penelitian bahwa umur ibu dikatakan beresiko tinggi apa bila ibu hamil berada dibawah 20 tahun karena alat reproduksi wanita belum matang dan beresiko pula apabila umur di atas 35 tahun karena fungsi organ reproduksi sudah mulai menurun. Pada umur terlalu muda banyak yang mengalami abortus karena uterusnya masih belum matang untuk tempat implantasi atau belum mampu untuk membawa janin dalam rahimnya, sedangkan pada umur yang terlalu tua yaitu karena berkurangnya fungsi alatalat reproduksi dan melemahnya atau berkurangnya efektifitas sebagai tempat implantasi pada umur mencapai >35 tahun.

Berdasarkan hasil penelitian yang dilakukan dari 42 orang (100\%) terdapat 19 orang $(23,8 \%)$ yang mengalami abortus pada primigravida diketahui bahwa terjadi abortus inkomplit sebanyak 12 orang $(28,6 \%)$ abortus imminens sebanyak 5 orang $(11,9 \%)$ dan missed abortus sebanyak 2 orang $(4,8 \%)$, dari 12 orang $(42,2 \%)$ yang mengalami abortus pada multigravida diketahui bahwa terjadi abortus inkomplit sebanyak 6 orang $(14,3 \%)$, abortus imminens tidak ada, dan missed abortus sebanyak 6 orang $(14,3 \%)$, dari 11 orang $(31,0 \%)$ yang mengalami abortus pada Grandemultigravida dapat diketahui 
bahwa terjadi abortus inkomplit sebanyak 3 orang $(7,1 \%)$, abortus imminens sebanyak 1 orang $(2,4 \%)$, dan missed abortus sebanyak 7 orang $(16,7 \%)$.

Berdasarkan hasil uji chi-square yang dilakukan oleh peneliti memperlihatkan bahwa nilai $p$ sebesar 0,017 berarti ada hubungan antara paritas dengan abortus.

Penelitian Yuliasih didapati ibu hamil yang mengalami abortus imminens pada kelompok usia $<20$ tahun sebanyak 37 orang $(52,9 \%)$ dikarenakan pada usia tersebut ibu belum mengetahui tentang kehamilan yang sehat dan tanda-tanda bahaya kehamilan yang menyebabkan abortus, lain halnya dengan kelompok paritas, dimana ibu hamil mengalami abortus imminens pada paritas primigravida dikarenakan kelompok paritas primigravida belum matangnya uterus dalam menerima proses kehamilan untuk yang pertama kalinya (Yuliasih, 2016).

Paritas ibu terbagi atas paritas tinggi dan paritas rendah. Menurut asumsi penelitian bahwa abortus terjadi pada ibu-ibu paritas rendah karena memiliki faktor-faktor tertentu salah satunya yaitu ibu-ibu masih kurang memahami kehamilanya, dan pentingnya pemeriksaan kehamilan. Sedangkan paritas tinggi sangat berpengaruh dalam kejadian abortus sebab kehamilan yang berulang-ulang menyebabkan rahim menjadi abnormal. Paritas dengan jumah kehamilan bayi sangat berkaitan dengan jarak kelahiran, semakin tinggi paritasnya maka senakin pendek jarak kelahiran. Paritas yang lebih tinggi, besar kemungkinan bayinya akan lahir sebelum waktunya (prematur) dengan berat badan rendah, abortus dan kemungkinan akan meninggal sebelum berusia 1 tahun.

Berdasarkan hasil penelitian yang dilakukan dari 42 orang (100\%) terdapat 3 orang $(7,1 \%)$ ibu yang mengalami abortus pada tingkat pendidikan TK/SD sebanyak 3 orang $(7,1 \%)$, bahwa terjadi abortus inkomplit sebanyak 3 orang $(7,1 \%)$, abortus imminens tidak ada, dan missed abortus tidak ada, dari 13 orang $(31,0 \%)$ ibu yang meng nbalami abortus pada tingkat pendidikan SMP sebanyak 13 orang (31,0\%), abortus inkomplit sebanyak 6 orang $(14,3 \%)$, abortus imminens sebanyak 5 orang (11,9\%), dan missed abortus sebanyak 2 orang $(4,8 \%)$, dari 19 otang $(45,2 \%)$ ibu yang mengalami abortus pada tingkat SMA diketahui bahwa terjadi abortus inkomplit sebanyak 11 orang $(26,2 \%)$, abortus imminens sebanyak 1 orang (2,4\%) dan missed abortus sebanyak 1 orang $(2,4 \%)$, dari 7 orang $(16,7 \%)$ ibu yang mengalami abortus pada tingkat pendidikan PT bahwa terjadi abortus 
inkomplit sebanyak 1 orang $(2,4 \%)$, abortus iminnes 0 orang $(0 \%)$ dan missed abortus sebanyak 6 orang $(14,3 \%)$.

Berdasarkan hasil uji chi-square yang dilakukan oleh peneliti memperlihatkan bahwa nilai $\rho$ sebesar 0,004 berarti ada hubungan antara pendidikan dengan abortus.

Berdasarkan hasil penelitian yang dilakukan oleh Noer, Ermawati, dan Afdal, data diambil dengan cara melihat data sekunder dari rekam medik pasien menunjukkan bahwa angka kejadian abortus adalah 5,83\% ibu yang pernah mengalami abortus lebih banyak berada dikelompok usia dibawah 20 tahun dan diatas 35 tahun, paritas lebih dari 3, pernah mengalami abortus sebelumnya, usia kurang darin 12 minggu, tidak bekerja dan pendidikan terakhir SD, SLTP dan SLTA dibanding dengan ibu yang mengalami abortus. Hal ini menunjukan bahwa usia ibu, usia kehamilan, pekerjaan dan pendidikan mempengaruhi terjadinya abortus (Noer, Ermawati, \& Afdal, 2016).

Menurut asumsi yang dilakukan penelitian dapat diketahui kejadian paling tinggi pada tingkat SMA dengan jumlah sebanyak 19 orang. Semakin tinggi pendidikan seseorang, semakin mudah pula mereka menerima informasi, dan pada akhirnya pengetahuan yang dimilikinya akan semakin banyak, sebaliknya jika seseorang memiliki tingkat pendidikan yang rendah, maka akan menghambat perkembangan sikap orang tersebut terhadap penerimaan informasi tentang kehamilan dan kejadian abortus yang dapat terjadi.

\section{KESIMPULAN DAN SARAN}

\section{Kesimpulan}

Ada hubungan umur ibu dengan abortus diperoleh hasil uji chi-square $p$ value $(0,002)$.

Ada hubungan paritas ibu dengan abortus diperoleh hasil uji chi-square $p$ value $(0,017)$.

Ada hubungan pendidikan ibu dengan abortus diperoleh hasil uji chi square $p$ value $(0,004)$.

\section{Saran}

Diharapkan kepada ibu agar lebih menjaga kehamilanya dan memeriksakan kehamilan ibu jika merasa ada tanda-tanda bahaya pada kehamilanya, agar tidak terjadi abortus dan komplikasi lainya.

\section{DAFTAR PUSTAKA}

Aini, D. (2016). Faktor-faktor yang berhubungan dengan kejadian abortus di RSUD Kelet Kabupaten Jepara Provinsi Jawa Tengah. Jurnal Jepara, 73-84.

Walyani, E. S. (2015). Perawatan kehamilan dan menyusui anak pertama agar bayi lahir dan tumbuh sehat. Yogyakarta: Pustaka Baru Press. 
Juwaher. (2010). Komunikasi terapeutik terhadap intensitas nyeri persalinan.

Mandriwati, N. A. (2020). Asuhan kebidanan dan kehamilan berbasis kompetensi. Jakarta: EGC.

Muhammad, I. (2020). Pemanfaatan SPSS dalam penelitian bidang kesehatan \& umum. Bandung: Citapustaka Media Perintis.

Noer, Ermawati, \& Afdal (2016). Karakteristik ibu pada penderita abortus dan tidak abortus. Kesehatan Andalas, 575-83.

Handayani, P. (2014). Hubungan umur ibu hamil dengan kejadian abortus di RSUD Abrawa. Abrawa .

Pariani, D. N. (2020). Faktor resiko yang berhubungan dengan kejadian abortus spontan di RSUD Unggaran. Jurnal Unggaran.

Pribadi, A. J. (2015). Kehamilan resiko tinggi. Jakarta: CV. Sagung Seto.

Rasidah. (2015). Hubungan karakteristik ibu hamil dengan kejadian abortus di RSU Haji Medan. Jurnal Umum.

Rukiyah, A. (2013). Asuhan kebidanan IV (Patologi kebidanan). Jakarta: Trans Info Media.

Walyani, E. (2015). Asuhan kebidanan pada kehamilan. Yogyakarta: Pustaka Baru Press.

Yuliasih. (2016). Hubungan karakteristik ibu hamil dengan terjadinya abortus imminens di RSUD dr. RM Djoelham Binjai. 